\title{
Research on the path of revitalizing rural tourism from the perspective of smart tourism
}

\author{
Lei Zhao ${ }^{1, *}$, Die Zhang ${ }^{2}$ \\ ${ }^{1}$ School of Tourism and Management, Wuhan Business University, Wuhan, Hubei, China \\ ${ }^{2}$ School of Tourism and Management, Wuhan Business University, Wuhan, Hubei, China
}

\begin{abstract}
Smart tourism is a highly systematic, efficient and convenient tourism mode. The development of rural tourism should evolve in the Internet era, and explore the industrial path of smart rural tourism. This paper discusses the developing opportunity of rural tourism in perspective of smart tourism, studies the developing status of rural tourism in the context of smart tourism, shape rural tourism by using the Internet information mode, and finally summarizes the development path of smart rural tourism.
\end{abstract}

\section{Introduction}

With the process of world integration, the spatial distance between urban and rural areas is constantly narrowing. Internet plus life has become background colour of daily life, and the concept of smart tourism is gradually being realized. Development of rural tourism in China has placed under the spot in recent years, breeding many new measures in resource development and utilization, brand promotion and so on. The path development and planning of rural tourism can make full use of Internet resources, strengthen the dissemination of tourism information, and introduce intelligent and information-based tourism service facilities, to meet the diversified tourism needs of tourists. ${ }^{[1]}$

\section{The current situation of rural tourism development under the background of smart tourism}

With the proposal of Rural Revitalization policy, the construction of beautiful and livable rural areas with natural resources and beautiful scenery has become a hot topic in social media. Driving the common development of urban and rural areas through "Tourism +" has become an important implementing the Rural Revitalization Strategy. ${ }^{[2]}$ The National Tourism Planning Bureau has allocated tourism funds to focus on the construction of new types of tourism projects such as leisure tourism, vacation tourism, rural tourism and cultural tourism, with tourism development plan to find new direction in the tourism reform. Considering the external situation and its own needs, Hubei Province has put forward policies and plans to stimulate investment vitality, improve the development environment, strengthen planning guidance and classification guidance, and promote the development of rural tourism, so as to make breakthroughs in rural tourism in close cooperation with various parties, under the national policies. ${ }^{[3]}$ At the same time, with the improvement of living standards, tourism has changed from small group entertainment to mass entertainment. In the past, the travel mode of single group tour has been changed into domestic and overseas multi variety travel, such as group travel, free travel and individual travel. Due to the high pressure of work and life, fast pace and short holidays, the contradiction between the continuous growth of tourism demand and limited tourist attractions has become increasingly prominent. Long distance travel seems to be more timeconsuming and laborious. Peripheral travel and rural travel have gradually become new travel options for urban leisure and entertainment. ${ }^{[4]-[5]}$

\section{The existing problems in rural tourism development}

\section{1 tourism facilities are backward and the intelligent foundation is weak}

Smart tourism is a highly embedded integration of information industry and tourism industry. Smart rural tourism cannot survive without basic information construction. At present, the coverage of rural information network in China is good. $4 \mathrm{G}$ network and broadband network have been implemented recently, but the condition of information infrastructure is not strong enough. For example, the organization decision-making information system, operation and maintenance management information system, information security and guarantee system have not been effectively operated and maintained, and the informatization level of government affairs processing is limited, and the application level of enterprise informatization production and operation is low. ${ }^{[6]}$ The development and utilization of tourism information resources is not high, and the

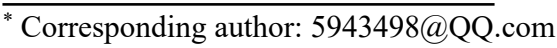


ability of network information acquisition and integration is poor. However, rural tourism information is scattered, messy, old, and updated slowly in Hubei province. In addition, the industry chain of rural tourism in Hubei Province is not strong enough. The construction of online and offline public service platforms is not in place, the industry standards are not uniform, and there is a lack of theoretical and practical guidance, the medical, health, transportation, service and other public facilities are not complete, and the service supporting capacity is insufficient, It is difficult to guarantee the maintenance of the health environment, the acquisition of emergency medical rescue, the smooth flow of rural roads, the experience of standardized services, and the early warning of tourism crisis information in scenic spots. The popularity of $\mathrm{Wi}-\mathrm{Fi}$, intelligent tour guide, online reservation, mobile payment, and traffic monitoring is low. The circulation of resources such as new knowledge, new technology, new information, new policies and compound talents is blocked, and the construction of specialized, standardized, creative and intelligent rural tourism faces great challenges.

\section{2 lack of product features and brand awareness}

The early rural tourism was mainly "farmhouse entertainment", represented by rural tourism activities such as courtyard, heatable adobe sleeping platform, overnight in farmhouse, eating farmhouse meal and doing farm work. The low price of tourism products was a natural choice at that time, but it also became a bottleneck restricting the development of rural tourism. Actually, each village has its own unique tourism resources. The folk custom, style, architecture and specialty are different in different places, which are the key factors of rural tourism attraction. However, due to the regional and economic constraints, domestic rural tourism is basically operated by its own, and there is no effective integration of resources. The self-sufficient farming life has lost its competitive advantage. Most of the rural tourism has not been deeply integrated with the Internet. Although some farmers have also joined in picking, barbecue and fishing, the forms are not many, the regions are scattered, and the regional joint development of short-term and long-term and network layout is not much..$^{[7]}$ Tourism gradually developing into personalized tourism and Internet. The monotonous and similar products of farmhouse tourism can no longer meet people's personalized needs. The main brand of rural tourism at home and abroad has not been formed.

\section{3 the management mode is chaotic and the marketing ability is weak}

Linkage, innovation and intelligence are the important characteristics of the construction of rural smart tourism. As an emerging tourism mode in the early stage of development and rectification, it is necessary to link with various parties, build and create together, and manage smart planning on the basis of complete infrastructure and supporting facilities. At present, the access threshold of rural tourism is low in Hubei Province, and the management quality of all parties is uneven. For example, the government lacks supervision and governance in tourism planning and policy implementation; the industry and commerce, tourism, planning and inspection departments do not go deep enough; a comprehensive governance system of joint management has not been formed; enterprises are independent in industrial integration, product development, operation and management; there is less cross regional, cross industry and cross field cooperation and exchange; the situation of win-win cooperation and integration of linkage and multi enterprises has not been widely formed; the relevant employees are mostly agricultural workers, without professional pre job training, low awareness of construction, lack of sense of responsibility, lack of service knowledge, weak service awareness, lack of good management and innovative thinking, and low overall quality of comprehensive service. As a result of above reasons, service and experience are highly homogeneous, while the price, quality and service standards are different, and events such as customer slaughtering, sky high price, dirty and poor are more frequent. ${ }^{[8]}$

The emergence of these situations is that rural tourism in some rural areas is just in its infancy, and the surrounding areas do not drive the relevant rural tourism revenue. To explore the reasons, on the one hand, the current development of rural tourist attractions has not yet reached a mature stage, and the supporting facilities such as accommodation, catering, transportation and entertainment are not perfect. On the other hand, because of the lack of publicity, people in surrounding cities simply do not know where to go for rural tourism. It is not easy for small villages to develop tourism projects. The main body of construction mainly depends on the village committee of the local natural village. In terms of human and financial resources, it is not enough to do a good job in development and publicity. Most of the management and publicity personnel are farmers themselves, lack of publicity means and knowledge, few applications for the Internet and new media, and mostly rely on word of mouth, so the source of tourists is also insufficient.

\section{On the path of rural tourism revitalization under the background of smart Tourism}

\subsection{Improve rural tourism supporting facilities, establish rural tourism information data platform}

The village tourist attractions have their own characteristics and tourism resources are scattered. Internet technology can be used to integrate rural geographic information resources, humanistic information resources, folk art resources, establish an intelligent tourism basic service system, establish a 
national network 3D three-dimensional rural tourism map, excellent rural guide retrieval information software, rural tourism route travel agency guide, etc. It can provide the most cutting-edge and fast professional services for smart rural tourism. At the same time, it provides perfect public infrastructure such as scenic spot transportation, network, medical and health care, fitness and so on, which is the hardware guarantee for the realization of smart tourism. To coordinate the infrastructure construction of villages and towns in Suizhou Hubei province, including rural environment improvement (water, toilet, wireless network coverage), upgrading of village roads, establishment of Suizhou rural tourism service big data linkage management platform, integration of Suizhou rural tourism information on food, housing, transportation, tourism, shopping, entertainment, etc. We have systematically promoted the construction of beautiful villages such as green landscape, rural housing transformation, clean and beautiful homes, industrial support and rural management, creating a new landscape with a string of pearls and bright spots. It can carry out the pilot construction of tourism mobile phone intelligent software in places with mature infrastructure construction, and provide intelligent navigation, online booking, electronic voice explanation and other services, so that tourists can have a new experience.

\subsection{Build a smart tourism marketing system and enhance the awareness of brand subject}

Highlighting the theme of rural tourism, giving full play to the unique resource advantages, adhering to the festival of cultural characteristics, stimulating the popularity of scenic spots, enhancing the city's popularity, have had a profound impact at home and abroad. Through a series of tourism culture related music and Culture Festival, Tea Picking Festival, Food festival, Beer festival and a series of unique festival activities, it can enhance the awareness of brand subject, produce considerable economic and social benefits, and effectively promote the development of rural tourism.

Rural tourism should adopt diversified marketing strategies to enhance its image, taking various festivals as an opportunity to strengthen the publicity and promotion of rural tourism through traditional media and emerging network media, travel agencies and tourism hotels; strengthen network marketing, especially new media and media marketing, cooperation with Taobao, Ctrip tourism website and others, holding "special limited time rural tourism special sale" and other similar activities to expand popularity; carrying out experiential service marketing, building the brand of rural tourism.

\section{Conclusion}

Smart tourism is a systematic and intensive comprehensive tourism service system. According to the current rural smart tourism in Hubei Province, this study puts forward the development path of rural tourism from the perspective of smart tourism. It takes co-creation and sharing as the basic principle of planning and construction, and takes the government, enterprises, residents and tourists as the main participants to do a good job in smart and innovative marketing mode, strives to make the wisdom throughout the whole process of rural tourism construction in China, covering all-round, all space, all industry, all elements.

At the same time, smart rural tourism is an important part of national smart tourism and smart life. With the continuous development of the Internet in the world, new media and technology provide new impetus for the development of rural tourism. Relevant governments and departments can cooperate with tourism enterprises, use Internet technology to scientifically plan, publicize and build a smart rural tourism system, choose their own smart rural tourism development mode, promote local characteristic rural culture, attract more tourists and drive the development of surrounding economy, and lead the new fashion of rural tourism.

Moreover, seeking truth from facts and steady and solid efforts to promote rural intelligence tourism construction is related to the adjustment and upgrading of industrial structure in rural areas, which is related to the integration and development of urban and rural integration. It concerns the ecological protection and cultivation of lucid waters and lush mountains are invaluable assets. It is an effective and reliable development path to revitalize the countryside by comprehensively coordinating the favorable resources such as policies, human resources, material resources and financial resources and promoting the construction of rural smart tourism, which provides ideas, direction and guarantee for continuously highlighting rural characteristics, promoting rural culture and building modern countryside.

\section{References}

1. Bao Runhua, Research on theory and practice of smart tourism $[\mathrm{M}]$. Chengdu University of Electronic Science and Technology Press, 8(2017)

2. Wen $\mathrm{Pu}$, Research on intelligent development of Guilin rural tourism industry [J]. Shanxi Agricultural Economics, 1(2019)

3. Chen Xuyun, Liang Chunshu, Chen Liqing, Mo Xiao Xiong, The promotion path of characteristic rural tourism under the Internet plus background [J]. Value Engineering, 2(2019)

4. Li Yuanyuan, Research on the development strategy of rural smart tourism [J]. Modern marketing, 5(2019)

5. Wang Yan, Research on promoting rural tourism development in Yantai with smart tourism platform [J]. Agricultural economy, 8(2019)

6. Zhang Zhong, Analysis of puzzlement and Countermeasures of rural smart tourism development in Henan Province [J]. Tourism overview (second half), 8(2019)

7. Ma Xuan Xuan, Explore the sustainable development strategy of rural tourism in the Internet 
plus era $[\mathrm{J}]$. Modern marketing (Business Edition), 9(2019)

8. Ma Jie, Path of sustainable development of rural tourism in Internet plus era $[\mathrm{J}]$. China Business Theory, 9(2019) 